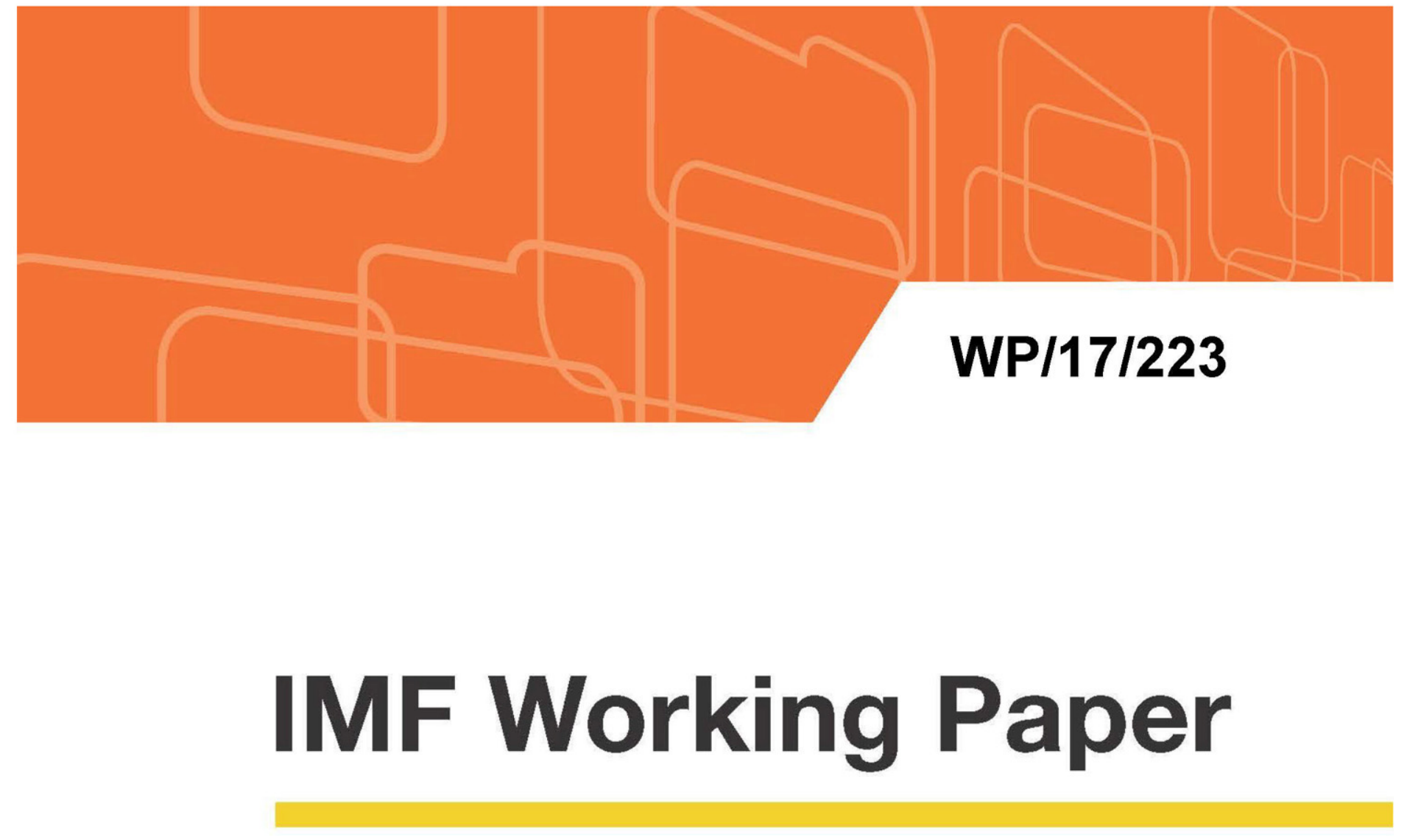

\title{
Building Resilience to Natural Disasters: An Application to Small Developing States
}

by Ricardo Marto, Chris Papageorgiou, and Vladimir Klyuev

IMF Working Papers describe research in progress by the authors and are published to elicit comments and to encourage debate. The views expressed in IMF Working Papers are those of the authors and do not necessarily represent the views of the IMF, its Executive Board, or IMF management. 


\section{WP/17/223}

\section{IMF Working Paper}

\section{Building Resilience to Natural Disasters: An Application to Small Developing States}

by Ricardo Marto, Chris Papageorgiou, and Vladimir Klyuev

IMF Working Papers describe research in progress by the authors and are published to elicit comments and to encourage debate. The views expressed in IMF Working Papers are those of the authors and do not necessarily represent the views of the IMF, its Executive Board, or IMF management.

$$
\text { I N T E R N A T I O N A L M O N E T A R Y F U N D }
$$




\title{
IMF Working Paper
}

Research Department and Strategy, Policy, and Review Department

\section{Building Resilience to Natural Disasters: An Application to Small Developing States* Prepared by Ricardo Marto, Chris Papageorgiou, and Vladimir Klyuev}

Authorized for distribution by Chris Papageorgiou

October 2017

\begin{abstract}
IMF Working Papers describe research in progress by the author(s) and are published to elicit comments and to encourage debate. The views expressed in IMF Working Papers are those of the author(s) and do not necessarily represent the views of the IMF, its Executive Board, or IMF management, or U.K. DFID.
\end{abstract}

\begin{abstract}
We present a dynamic small open economy model to explore the macroeconomic impact of natural disasters. In addition to permanent damages to public and private capital, the disaster causes temporary losses of productivity, inefficiencies during the reconstruction process, and damages to the sovereign's creditworthiness. We use the model to study the debt sustainability concerns that arise from the need to rebuild public infrastructure over the medium term and analyze the feasibility of ex ante policies, such as building adaptation infrastructure and fiscal buffers, and contrast these policies with the post-disaster support provided by donors. Investing in resilient infrastructure may prove useful, in particular if it is viewed as complementary to standard infrastructure, because it raises the marginal product of private capital, crowding in private investment, while helping withstand the impact of the natural disaster. In an application to Vanuatu, we find that donors should provide an additional $50 \%$ of pre-cyclone GDP in grants to be spent over the following 15 years to ensure public debt remains sustainable following Cyclone Pam. Helping the government build resilience on the other hand, reduces the risk of debt distress and at lower cost for donors.
\end{abstract}

JEL Classification Numbers: E22, E62, F34, F35, H54, H63, H84, O23, Q54.

Keywords: Natural Disastes, Resilience, Adaptation, Debt Sustainability, Small States.

Authors’ E-Mail Addresses: rmarto@imf.org, cpapageorgiou@imf.org, vklyuev@imf.org.

\footnotetext{
* Authors are grateful to seminar participants at the IMF for their useful comments, suggestions, and advice. This working paper is part of a research project financed by the U.K.'s Department of International Development (DFID) to support macroeconomic research on Low Income Countries. The views expressed in this paper are those of the authors and do not necessarily represent those of the IMF, or of IMF policy, or of DFID.
} 


\section{Contents}

Page

1. Introduction $\quad \underline{3}$

2. The Model $\quad \underline{6}$

$\begin{array}{lll}\text { 3. Calibration } & \underline{12}\end{array}$

4. Recovering with Fiscal and Debt Sustainability $\quad \underline{\mathbf{1 8}}$

4.1. Alone in the Dark . . . . . . . . . . . . . . . . . . . $\underline{18}$

4.2. Grants for Reconstruction ..................... 19

5. Building Resilience with Adaptation Infrastructure and Fiscal Buffers $\underline{\mathbf{2 0}}$

5.1. Investing in Resilient Infrastructure . . . . . . . . . . . . . . 20

5.2. Building Fiscal Buffers . . . . . . . . . . . . . . . . . . 21

6. Conclusions $\quad \underline{24}$

References $\quad \underline{26}$

Figures

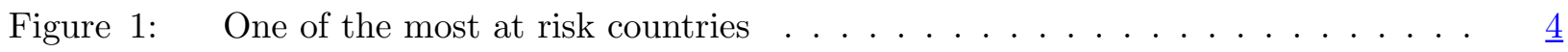

Figure 2: The natural disaster's transmission channel . . . . . . . . . . $\underline{15}$

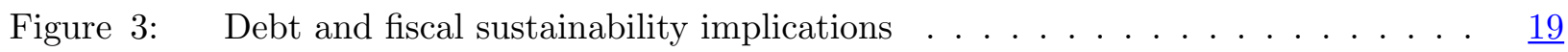

Figure $4: \quad$ More resilient infrastructure, lower damages . . . . . . . . . . . . $\underline{21}$

Figure 5: Resilient infrastructure reduces risk of debt distress . . . . . . . . . $\underline{22}$

Figure 6: Saving in a contingency fund helps smooth the recovery . . . . . . . $\underline{23}$

\section{Tables}

Table $1: \quad$ Selected initial values $(\%) \ldots \ldots \ldots \ldots \ldots \ldots$

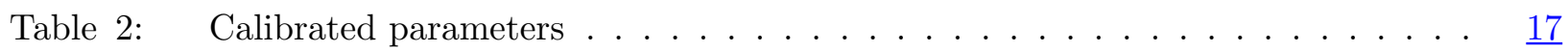




\section{Introduction}

Small developing states are among the most vulnerable countries in the world to natural disasters and climate change. The UN World Risk Index, which measures exposure to natural hazards and the capacity to cope with these events across 171 countries, places small developing states at the top of its ranking. In addition to the limited capacity to respond to natural disasters, these countries are more frequently hit by extreme weather events than larger countries and their economic costs are on average much larger (IMF, 2016a). Climate change will only worsen the reach of natural disasters, by increasing their intensity and frequency (IPCC, 2014). This vulnerability to natural disasters exacerbates the challenging tradeoff policymakers face domestically - allocating spending for growth-promoting infrastructure or vulnerability-reducing resilience - and externally by the donor community - allocating financial support pre or post-disaster.

Boosting infrastructure investment has gained renewed attention as an imperative for economic development. It encourages private investment and increases productivity, and fosters inclusion by improving connectivity and allowing people to spend their time on more productive activities. Improving infrastructure is indispensable for attaining the Sustainable Development Goals and it is regularly included as a key pillar of countries' national development strategies. Particularly important in this context are the links between infrastructure and climate change. The links run in two directions. First, certain types of infrastructure may contribute to climate change (e.g., coal power plants increase greenhouse gas emissions) or environmental degradation (such as dams or roads). Second, given that climate change will manifest itself in an increased frequency and severity of extreme weather events, building resilient infrastructure - capable of withstanding such events - becomes paramount. It is thus critical to be mindful of the tradeoffs involved in deciding how much and what type of infrastructure to install and to take mitigating measures where and when necessary. Otherwise, economic and social costs after storms and other climate-related shocks will be unbearable.

One of the most devastating natural disasters in the Pacific region's history, the category five cyclone - Cyclone Pam - ravaged Vanuatu in March 2015 and inflicted damages and losses of about 60 percent of the archipelago's GDP and affected more than 188,000 inhabitants (more than 70 percent of the population). The main productive sectors were highly affected, with damages to tourism and transport infrastructure estimated at 11 percent of GDP, and production losses in agriculture and tourism equivalent to 14 percent of GDP. Vanuatu's limited landmass, aggravated by the double insularity of outer islands, and high population and infrastructure densities in coastal areas make it particularly prone to natural disasters - ranking first as the most country at risk by the UN World Risk Index (Figure 1) - and provides therefore an appropriate background for this analysis. The probability of a natural disaster happening in Vanuatu in any given year is 65 percent and more than 99 percent in a five-year period. According to EM-DAT, which provides estimates of human and economic costs by type of disaster, natural disasters caused annual damages equivalent to 2.4 percent of GDP over the 1950-2014 period and affected more than 3 percent of the population. In addition to natural disasters, the cumulative impact of non-extreme but prolonged weather events, such as the El Niño's droughts and La Niña's heavy rainfall, has put the country further at risk. On the other hand, the effects of climate change, including sea-level rise, coastal erosion, overstressed water resources, unstable rainfall, 
floods, and droughts, pose a severe challenge to the development process of most small states - and Vanuatu in particular. According to Burke et al. (2015), GDP per capita is expected to drop by 75 percent by 2100 relative to a world without climate change (with a 97 percent probability that climate change will reduce GDP per capita by more than 50 percent), making Vanuatu's population poorer and incomes diverging from-rather than converging to - other developing economies.

Figure 1: One of the most at risk countries

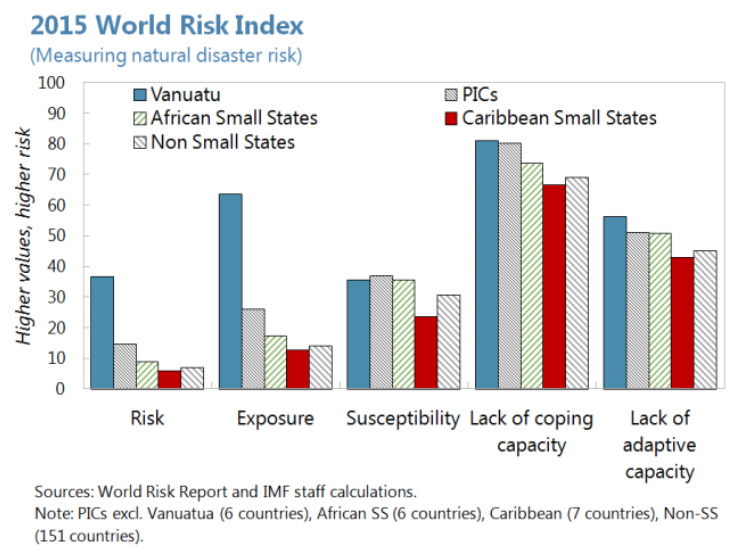

With that background in mind, this paper introduces a small open economy model to analyze how small developing states could build resilience to and recover from natural disasters. Calibrated to a small, low-income economy like Vanuatu, we use the model to assess the government's intent of swiftly rebuilding the damaged public infrastructure after Cyclone Pam and study what set of policies could have been put in place to smoothen the response to Cyclone Pam and how developing partners could have supported the recovery. In particular, the paper addresses the following questions: (i) considering the government's intent of rebuilding the damaged public infrastructure in a relatively short time span (about 6 years), how much funding would donors have to provide to ensure debt remains sustainable over the medium term without further fiscal consolidation?; and (ii) if donors had supported investments in resilient infrastructure and helped build up the contingency fund in advance of the disaster, what would Vanuatu's public debt profile look like?

In this model, the government can invest in standard infrastructure (e.g., roads) as well as in adaptation capital (e.g., seawalls). Adaptation capital, in addition to contributing to the overall quality of infrastructure in the country (which enters the production function of private firms), reduces the damages inflicted by a natural disaster. It is combined with standard public capital in a CES function, which permits exploring the implications of different degrees of complementarity between standard and adaptation capital - departing from the roads vs. seawalls distinction to a finer resemblance between the two, such as climate-proofing roads to withstand stronger natural disasters. In addition to investing in resilient infrastructure, the government can save resources in an external contingency fund that can then be used to finance reconstruction activities. The contingency fund sits in a major financial center and pays the risk-free interest rate.

The model thus allows to analyze the following issues. First, adaptation vs. reconstruction; 
building more resilient infrastructure is costly, but it reduces the immediate impact of natural disasters on output as well as the cost of post-disaster recovery. Second, financial buffers vs. physical resilience; with limited access to financial markets, financing a post-disaster recovery presents a challenge for a small developing state and therefore policymakers may want to prepare ex ante. As an alternative to building more resilient infrastructure, the government could accumulate assets in a contingency fund to be used after a natural disaster. Finally, it also allows to contrast alternative paths of postdisaster reconstruction; the model can compare the implications for growth and debt sustainability of alternative trajectories for rebuilding public capital after a given natural disaster as well as of alternative financing modes (tax increases, domestic borrowing, and external concessional and nonconcessional borrowing).

Our results suggest that in order for these small developing states to recover smoothly and ensure a steady convergence process to their peers, bilateral and multilateral donors would have to pitch in significant amounts of financial resources post-disaster - even if reasonable resources are dedicated to building resilience prior to the disaster. Investing in resilient infrastructure and building a contingency fund are complementary measures to smooth the impact of the disaster and ensure a swift recovery once infrastructure starts being rebuilt. However, without a strong support from development partners, rebuilding public capital in a short time horizon demands either a strong fiscal adjustment or the availability of (domestic or external) borrowing. In most cases, these instruments are not available or politically feasible. For instance, in the aftermath of the disaster, the government of Vanuatu suspended VAT and import duties on construction materials for two months after the cyclone, deferred the payments of vehicle registration fees and VAT payments to the next quarter, and provided subsidies for agricultural seedlings to affected households - reversing these policies and increasing taxes over the board would have been infeasible. Although domestic banks delayed loan repayments for 6 to 12 months to some corporate customers pending an insurance payout and provided additional lending to commence repair work, the availability of credit for the government was small. Alternatively, resorting to external borrowing (commercial or otherwise) was either not available or would require more months to negotiate and materialize. We thus argue that in those situations grant-financing post disaster is essential in order to ensure that the reconstruction of the damaged public infrastructure would not put at risk the country's debt sustainability position. So all in all, what is "grant-fathering?" It's the concept that for small open economies with limited access to external borrowing and a high import content of infrastructure projects, their governments would need a substantial amount of grantfinancing when hit by natural disasters - or any other large external shock, for that matter - and faced with huge reconstruction needs in order to ensure fiscal and debt sustainability over the medium term.

This paper relates to two strands of literature. The first is on the macroeconomic effects of public investment and in particular with what relates to fiscal and debt sustainability. Earlier work by Barro (1990), Barro and Sala-i-Martin (1992), Futagami et al. (1993) quantify the growth benefits of public investment, while Turnovsky (1999), among others, adds government debt to similar frameworks. More recently, Buffie et al. (2012) studied debt sustainability concerns that arise with alternative public investment programs and financing strategies for low income countries. Other papers have studied the relationship between aid and public investment, such as Adam and Bevan (2006). The other strand of literature is on the macroeconomic effects of natural disasters. Cavallo and Noy (2011) summarizes the state of the literature examining the aggregate impact of disasters, while Noy (2009) 
provides an empirical investigation on the macroeconomic costs of natural disasters. The latter finds that small economies face larger indirect economic impacts than larger ones; however, it does not assess the effects of natural disasters on the government budget and its indebtedness. Bevan and Cook (2015) focuses on the impact of disasters on public expenditures and the challenges disasters pose on financial public management. Cavallo et al. (2013) provides case studies of countries that had recently endured a natural disaster, using the synthetic control method to show the counterfactual economic growth. Becerra et al. (2014) conduct an event study of foreign aid inflows after natural disasters and find that aid surges cover about 3 percent of the estimated damages. Other papers have used structural models to look at these issues as well. Bakkensen and Barrage (2017) use an endogenous growth model to quantify the impacts of natural disasters on growth and welfare, drawing on the literature on incomplete markets. In a calibrated model, Borensztein et al. (2017) assess the welfare gains from insuring against natural disasters with catastrophe bonds. Bevan and Adam (2016) use a similar framework to ours and study disaster risk insurance as a mean to fund reconstruction. Ikefuji and Horii (2012) associate natural disasters with the use of pollutant inputs and argue that growth is sustainable if the tax rate on those inputs increases over time.

The remainder of the paper is organized as follows. Section II discusses the model and Section III presents the data used to calibrate the model and the experiments conducted. Section IV analyzes the macroeconomic impact of the natural disaster and Section V explores policies that could have been implemented prior to the disaster. The conclusion and policy implications are discussed in Section VI.

\section{The Model}

We introduce a two-sector small open economy model featuring a traded and nontraded goods sectors that are disparately affected by a natural disaster and a government that decides how to prepare for, and how to recover from, a natural disaster with alternative public financing instruments (domestic and external debt, grants, and consumption taxes) along the lines of Bevan and Adam (2016). There are five channels through which the economy is impacted by the natural disaster: (i) through permanent damages to public infrastructure; (ii) permanent damages to private capital; (iii) temporary losses of productivity resulting from the economic and social disruption (e.g., people are not able to work and have to spend time removing debris); (iv) increased inefficiencies in public investment during the reconstruction period; and (v) damages to the sovereign's creditworthiness. The framework accounts for all the apparatus involved in building resilience prior to a disaster - namely, government investment in adaptation infrastructure and fiscal buffers - to study a country's response to an extreme weather event.

\section{Firms}

Firms produce tradable and nontradable goods ( $y_{x}$ and $y_{n}$, respectively) according to a CobbDouglas production technology combining public infrastructure - a constant elasticity of substitution (CES) function of standard infrastructure $z^{i}$ and adaptation capital $z^{a}$ with productivity $\nu_{a}$ - with 
private capital $k_{j}$ and labor $l_{j}$. Firms operate in one single sector and benefit from a sector-specific total factor productivity (TFP) $A_{j}$. The natural disaster affects both sectors, but causes disparate damages $D_{j} \in[0,1]$ to output by permanently destroying public and private capital and resulting in a transitory loss of productivity. The impact of the natural disaster can however be counteracted by public investments in adaptation activities that reduce the extent of the damages (with $\pi_{j}$ and $\nu_{D}$ being scaling factors).

In each sector $j$, a firm maximizes profits according to

$$
\Phi_{j, t}=P_{j, t}\left(1-\frac{D_{j, t}}{\left(1+\pi_{j} z_{t-1}^{a}\right)^{\nu_{D}}}\right) y_{j, t}-w_{t} l_{j, t}-r_{j, t} k_{j, t-1}
$$

where $w$ is the economy-wide wage and $r_{j}$ is the sectoral return on capital in sector $j$. Output is defined as

$$
y_{j, t}=A_{j, t} z_{t-1}^{\psi_{j}} k_{j, t-1}^{\alpha_{j}} l_{j, t}^{1-\alpha_{j}} \quad \text { for } \quad j=n, x .
$$

and public capital as

$$
z_{t}=\left[\rho_{z}^{\frac{1}{\xi}}\left(z_{t}^{i}\right)^{\frac{\xi-1}{\xi}}+\left(1-\rho_{z}\right)^{\frac{1}{\xi}}\left(\nu_{a} z_{t}^{a}\right)^{\frac{\xi-1}{\xi}}\right]^{\frac{\xi}{\xi-1}},
$$

where $\rho_{z}$ is a weight parameter and $\xi$ is the intratemporal elasticity of substitution between public capital inputs (standard and adaptation). This functional form is particularly useful in discussing adaptation because it allows us to view it either as a substitute or a complement to standard infrastructure (e.g. seawalls vs. climate-proofing roads; see discussion in the calibration section). Note that damages can be decomposed into damages to public and private capital as well as losses of productivity according to $\left(1-D_{z_{j}}\right)=\left(1-\frac{D_{j}}{\left(1+\pi_{j} z^{a}\right)^{\nu D}}\right)^{\varpi_{z}},\left(1-D_{k_{j}}\right)=\left(1-\frac{D_{j}}{\left(1+\pi_{j} z^{a}\right)^{\nu}}\right)^{\varpi_{k}}$, and $\left(1-D_{A_{j}}\right)=\left(1-\frac{D_{j}}{\left(1+\pi_{j} z^{a}\right)^{\nu} D}\right)^{1-\varpi_{z} \psi_{j}-\varpi_{k} \alpha_{j}}$, respectively. The severity of the damages to public and private infrastructures is controlled by $\varpi_{z}$ and $\varpi_{k}$, respectively, such that the larger $\varpi_{z}$ is, the greater public infrastructure was destroyed relative to private capital and TFP (with $1-\varpi_{z} \psi_{j}-\varpi_{k} \alpha_{j} \geq 0$ ). The literature on natural disasters distinguishes damages from economic losses. We thus target the size of $D_{A_{j}}$ as representing economic losses and $D_{z_{j}}$ and $D_{k_{j}}$ as damages to physical infrastructure. The disruption in the functioning of public and private infrastructure has a persistent effect on the TFP because infrastructure takes some time to rebuild and workers may have spend to their time cleaning roads or rebuilding their houses, so aggregate productivity is assumed to recover slowly. ${ }^{1}$

Profit-maximizing firms demand capital and labor according to

$$
P_{j, t} \alpha_{j} \frac{y_{j, t}}{k_{j, t-1}}=r_{j, t} \quad \text { for } \quad j=n, x
$$

and

$$
P_{j, t}\left(1-\alpha_{j}\right) \frac{y_{j, t}}{l_{j, t}}=w_{t}{ }^{2}
$$

\footnotetext{
${ }^{1}$ By contrast, Bevan and Adam (2016) are interested in disaster risk and define the probability of a damaging disaster to follow a negative exponential distribution. Instead, we are focusing on a known disaster, for which aggregate damages to GDP are available.

${ }^{2}$ Labor is perfectly mobile across sectors and returns on private capital are sector-specific, except in the steady state.
} 
Output elasticities with respect to total public capital can also be derived as

$$
P_{j, t} \psi_{j} \frac{y_{j, t}}{z_{t-1}}=R_{t}^{z}
$$

where $R_{t}^{z}$ is the total return to public infrastructure, which can be expressed in terms of the returns to standard and adaptation infrastructure as $R_{t}^{z i}\left(\frac{z_{t-1}^{i}}{\rho_{z} z_{t-1}}\right)^{1 / \xi}$ and $R_{t}^{z a}\left(\frac{\nu_{a}^{1-\xi} z_{t-1}^{a}}{\left(1-\rho_{z}\right) z_{t-1}}\right)^{1 / \xi}$, respectively. Note that firms do not take into account the added benefit of adaptation (namely the protection against natural disasters) in their optimal decisions and only factor in the benefits of having additional infrastructure as an input in their production processes. Infrastructure prices are a function of the price of the imported machinery needed to produce capital, $P_{m m}$, and of the price of the $a_{j}(j=k, z i, z a)$ nontradable inputs needed to produce capital $P_{n}$. The price of private capital is given by $P_{k, t}=$ $P_{m m, t}+a_{k} P_{n, t}$. We allow public standard and adaptation infrastructures to have different imported and nontradable input contents to reflect the idea that adaptation infrastructure requires more technical inputs provided externally and sold at a premium $p r$ or that they demand more or less construction materials than the standard infrastructure. The prices of standard and adaptation infrastructure are thus given by $P_{z i, t}=P_{m m, t}+a_{z i} P_{n, t}$ and $P_{z a, t}=(1+p r) P_{m m, t}+a_{z a} P_{n, t}$, respectively.

\section{Government}

Government expenditures are directed to investments in standard and adaptation infrastructure $i_{z i}$ and $i_{z a}$, transfers to households $\mathcal{T}$, and servicing public domestic and external debt. The government also collects revenues from VAT on households' consumption and from fees on Ricardian households' usage of standard public infrastructure (as a fraction $f$ of recurrent $\operatorname{costs} \delta_{z i} P_{z i_{o}}$ involved in the maintenance of the infrastructure (i.e. $\left.\left.\mu=f \delta_{z i} P_{z i_{o}}\right)\right)^{3}$

As Dablas-Norris et al. (2012) shows, infrastructure stocks vary considerably in low-income countries despite high levels of investment. Therefore, the economy only benefits from effectively produced capital, which depends on public investment efficiency $s \in[0,1]$. The public investment process is equally bureaucratic and inefficient across the two capital inputs. To account for the increased inefficiencies that arise post-disaster, $s$ is time-varying and affected by $D_{s}$ at the time of disaster. In particular, the ability to transform each dollar spent into capital takes some time to recover, with expenses being lost in non-productive activities. Public capital therefore evolves according to

$$
\begin{aligned}
z_{t}^{i} & =\left(1-\delta_{z i}\right) z_{t-1}^{i}+\left(1-D_{s}\right) s_{t} i_{z i, t}, \\
z_{t}^{a} & =\left(1-\delta_{z a}\right) z_{t-1}^{a}+\left(1-D_{s}\right) s_{t} i_{z a, t} .
\end{aligned}
$$

Note that these two types of infrastructure depreciate at different rates in order to account for their different resilience to natural disasters. Adaptation infrastructure is able to better withstand the effects of climate change and natural disasters than standard infrastructure, and therefore $\delta_{z i}>\delta_{z a}$. Adam and Bevan (2014), in contrast, consider the case of operations and maintenance expenditures

\footnotetext{
${ }^{3}$ Liquidity-constrained households do not have to pay fees for using public infrastructure.
} 
affecting the level of depreciation of public capital to underline the need for accounting these in the government's budget constraint.

Another channel through which natural disasters can affect fiscal policy is through market interest rates. As S\&P (2015) points out natural disasters can, in addition to the physical destruction of infrastructure, damage a sovereign's creditworthiness. While the real interest rate on concessional debt is held constant $\left(r_{d, t}=r_{d}\right)$, the natural disaster shock weakens the sovereign's rating by $D_{r, t}$. And as common in the literature, large accumulations of external debt (in deviations from its steady state level) aggravate the country risk premium, in line with Schmitt-Grohe and Uribe (2003). Given the risk-free world interest rate $r^{f}$ and nominal GDP $\left(y_{t}=P_{n, t} y_{n, t}+P_{x, t} y_{x, t}\right)$, the real interest rate on external commercial debt follows

$$
r_{d c, t}=\left(1+D_{r, t}\right)\left(r^{f}+v_{g} e^{\eta_{g}\left(\frac{d_{t}+d_{c, t}}{y_{t}}-\frac{\bar{d}+\bar{d}_{c}}{\bar{y}}\right)}\right)
$$

In addition to building resilience with adaptation infrastructure, the government can decide to set up a fund to build up its savings against a natural disaster. Let $\mathfrak{s}_{t}$ be government savings in a bank abroad, paying real interest rate $r^{f}$, the fund can only be drawn down in case of a major natural disaster to finance the fiscal deficit that arises with reconstruction activities. In addition to this buffer, the government can finance its fiscal deficit with external grants $\mathcal{G}$ and a combination of tax adjustments and borrowing: external concessional debt $\Delta d_{t}=d_{t}-d_{t-1}$ as well as domestic $\Delta b_{t}=b_{t}-b_{t-1}$ and external commercial $\Delta d_{c, t}=d_{c, t}-d_{c, t-1}$ debt according to the rule $(1-v) \Delta b_{t}=v \Delta d_{c, t}$. The government budget constraint is thus given by

$$
\begin{aligned}
P_{z i, t} i_{z i, t}+P_{z a, t} i_{z a, t}+\mathcal{T}_{t}+r_{t-1} P_{t} b_{t-1}+ & \\
r_{d, t-1} d_{t-1}+r_{d c, t-1} d_{c, t-1}+\Delta \mathfrak{s}_{t} \leq & P_{t} \Delta b_{t}+\Delta d_{t}+\Delta d_{c, t}+r^{f}{ }_{\mathfrak{s} t-1}+ \\
& +\tau_{t}^{c} P_{t} c_{t}+\mu z_{t-1}^{e}+\mathcal{G}_{t} .
\end{aligned}
$$

We can rewrite the budget constraint above in terms of the fiscal gap ( $\mathfrak{G a p})$ as

$$
\mathfrak{G} \mathfrak{a p}_{t}=P_{t} \Delta b_{t}+\Delta d_{c, t}+\left(\tau_{t}^{c}-\tau_{o}^{c}\right) P_{t} c_{t}-\Delta \mathfrak{s}_{t}
$$

where $\mathfrak{G a p}_{t}=\mathfrak{E x p}_{t}-\mathfrak{R e v} \mathfrak{v}_{t}$, i.e. given by the difference between total expenditures and revenues when the consumption tax is kept at its initial value $\left(\tau_{o}^{c}\right)$ and concessional debt and grants are exogenous, is covered by domestic and external commercial borrowing, VAT adjustments, and/or savings withdrawals, such that

$$
\mathfrak{E x p}_{t}=P_{z i, t} i_{z i, t}+P_{z a, t} i_{z a, t}+\mathcal{T}_{t}+r_{t-1} P_{t} b_{t-1}+r_{d c, t-1} d_{c, t-1}+\left(1+r_{d}\right) d_{t-1}-d_{t}
$$

and

$$
\mathfrak{R e} \mathfrak{v}_{t}=r^{f} \mathfrak{s}_{t-1}+\tau_{o}^{c} P_{t} c_{t}+\mu z_{t-1}^{e}+\mathcal{G}_{t} .
$$

The fiscal rule for the consumption tax rate allows $\tau^{c}$ to respond to both tax and debt deviations 
from their target, with $\lambda_{1}$ controlling the response of the tax adjustment to the tax rate that would prevail if all the other financing instruments were not available to close the fiscal gap and $\lambda_{2}$ controlling the response to deviations from the debt target

$$
\tau_{t}^{c}=\tau_{t-1}^{c}+\lambda_{1}\left(\left(\tau_{t}^{c}\right)^{\text {target }}-\tau_{t-1}^{c}\right)+\lambda_{2} \frac{\left(P_{t-1} b_{t-1}+d_{c, t-1}\right)-\left(P b+d_{c}\right)^{\text {target }}}{y_{t}} \quad \forall \lambda_{1}, \lambda_{2} \geq 0 .
$$

where the tax target $\left(\tau_{t}^{c}\right)^{\text {target }}=\tau_{o}^{c}+\frac{\mathfrak{G a p}_{t}}{P_{t} c_{t}}$, ensuring debt sustainability in the long run. ${ }^{4}$ For the scenario analysis that we conduct, $\tau_{t}^{c}=\tau_{o}^{c}$ for the case in which the government finances its reconstruction entirely with borrowing and $\tau_{t}^{c}=\left(\tau_{t}^{c}\right)^{\text {target }}$ when the reconstruction program is entirely financed with taxes.

\section{Households}

The economy features two types of households: Ricardian and liquidity-constrained (denoted by $\mathfrak{r}$ and $\mathfrak{c}$, respectively), who consume tradable goods produced domestically $c_{x, t}$ and abroad $c_{m, t}$ as well as domestic nontradable goods $c_{n, t}$. The consumption basket is defined as the CES function

$$
c_{t}^{i}=\left[\rho_{x}^{\frac{1}{\epsilon}}\left(c_{x, t}^{i}\right)^{\frac{\epsilon-1}{\epsilon}}+\rho_{m}^{\frac{1}{\epsilon}}\left(c_{m, t}^{i}\right)^{\frac{\epsilon-1}{\epsilon}}+\left(1-\rho_{x}-\rho_{m}\right)^{\frac{1}{\epsilon}}\left(c_{n, t}^{i}\right)^{\frac{\epsilon-1}{\epsilon}}\right]^{\frac{\epsilon}{\epsilon-1}} \text { for } i=\mathfrak{r}, \mathfrak{c},
$$

where $\rho_{m}$ and $\rho_{x}$ are weights and $\epsilon$ is the intratemporal elasticity of substitution between consumption goods. The associated consumer price index is given by ${ }^{5}$

$$
P_{t}=\left[\rho_{x} P_{x, t}^{1-\epsilon}+\rho_{m} P_{m, t}^{1-\epsilon}+\left(1-\rho_{x}-\rho_{m}\right) P_{n, t}^{1-\epsilon}\right]^{\frac{1}{1-\epsilon}} .
$$

Ricardian households face the intertemporal optimization problem

$$
\max \sum_{t=0}^{\infty} \beta^{t} \frac{\left(c_{t}^{\mathfrak{r}}\right)^{1-1 / \varsigma_{c}}}{1-1 / \varsigma_{c}}
$$

where $\beta$ is the discount factor and $\varsigma_{c}$ is the intertemporal elasticity of substitution of consumption. In addition to consuming goods, this representative household invests in private tradable and nontradable capital $\left(i_{x}\right.$ and $i_{n}$, respectively), which encompasses some adjustment costs $A C_{j, t}^{\mathfrak{r}} \equiv$ $\frac{v}{2}\left(\frac{i_{j, t}^{\mathrm{r}}}{k_{j, t-1}^{\mathfrak{s}}}-\delta\right)^{2} k_{j, t-1}^{\mathfrak{r}}$; pays levies on standard public infrastructure $\mu z^{i}$; saves through domestic bonds $b$; and buys foreign debt $b^{*}$, which carries a real interest rate $r^{*}$ as well as portfolio adjustment costs $\Theta_{t}^{\mathfrak{r} *} \equiv \frac{\eta}{2}\left(b_{t}^{\mathfrak{r} *}-\overline{b^{\mathfrak{s *}}}\right)^{2}$, where $\overline{b^{\mathfrak{r} *}}$ is the steady-state value of external private debt. The government levies a value-added tax (VAT) $\tau^{c}$ on consumption, which affects both Ricardian and liquidity-constrained households.

\footnotetext{
${ }^{4}$ Buffie et al. (2012) also allow transfers to adjust and hence can be used as another policy instrument to close the fiscal gap.

${ }^{5}$ The foreign consumer price index $P_{t}^{*}$ is the numeraire.
} 
The income side of the household's budget constraint

$$
\begin{aligned}
\left(1+\tau_{t}^{c}\right) P_{t} c_{t}^{\mathfrak{r}}+\mu z_{t-1}^{i}+P_{t} b_{t}^{\mathfrak{r}}+\left(1+r_{t-1}^{*}\right) b_{t-1}^{\mathfrak{r} *}+ & \\
\Theta_{t}^{\mathfrak{r} *}+P_{k, t}\left(i_{n, t}^{\mathfrak{r}}+i_{x, t}^{\mathfrak{r}}+A C_{n, t}^{\mathfrak{r}}+A C_{x, t}^{\mathfrak{r}}\right) \leq & w_{t} l_{t}^{\mathfrak{r}}+r_{n, t} k_{n, t-1}^{\mathfrak{r}}+r_{x, t} k_{x, t-1}^{\mathfrak{r}}+\left(1+r_{t-1}\right) P_{t} b_{t-1}^{\mathfrak{r}} \\
& +b_{t}^{\mathfrak{r} *}+\frac{1}{1+a}\left(\mathcal{R}_{t}+\mathcal{T}_{t}\right)+\Phi_{t}^{\mathfrak{r}}
\end{aligned}
$$

is composed of an employment wage $w$ on labor $l^{\mathfrak{r}}$ supplied to firms; interest $r_{x}$ and $r_{n}$ received from tradable and nontradable capital, respectively; interest $r$ received on domestic bonds; a fraction of remittances $\mathcal{R}$ and government transfers $\mathcal{T}$ corresponding to the share of Ricardian households in the labor market; ${ }^{6}$ as well as profits $\Phi^{\mathfrak{r}}$ from owning domestic firms. The accumulation of private capital, which depreciates annually at rate $\delta_{k}$, is given by

$$
k_{j, t}^{\mathfrak{r}}=\left(1-\delta_{k}\right) k_{j, t-1}^{\mathfrak{r}}+i_{j, t}^{\mathfrak{r}} \quad \text { for } j=n, x
$$

The solution to the household's constrained maximization problem yields the consumption Euler equation

$$
c_{t}^{\mathfrak{r}}=c_{t+1}^{\mathfrak{r}}\left[\beta\left(1+r_{t}\right) \frac{1+\tau_{t}^{c}}{1+\tau_{t+1}^{c}}\right]^{-\varsigma_{c}},
$$

and the non-arbitrage conditions defining that the returns on tradable and nontradable capital equate the return on domestic bonds

$$
\begin{aligned}
\left(1+v \Upsilon_{j, t}^{\mathfrak{r}}\right)\left(1+r_{t}\right)\left[\frac{P_{t+1}}{P_{t}} \frac{P_{k, t}}{P_{k, t+1}}\right]= & \frac{r_{j, t+1}}{P_{k, t+1}}-\frac{v}{2}\left(\Upsilon_{j, t+1}^{\mathfrak{r}}\right)^{2}+ \\
& v \Upsilon_{j, t+1}^{\mathfrak{r}}\left[\frac{i_{j, t+1}^{\mathfrak{r}}}{k_{j, t}^{\mathfrak{r}}}+(1-\delta)\right]+(1-\delta),
\end{aligned}
$$

where $\Upsilon_{j, t}^{\mathfrak{r}}=\left(\frac{i_{j, t}^{\mathfrak{r}}}{k_{j, t-1}^{\mathfrak{r}}}-\delta\right)$ for $j=n, x$, and that the return on domestic bonds equates the return on external private debt

$$
\left(1+r_{t}\right) \frac{P_{t+1}}{P_{t}}=\frac{\left(1+r_{t}^{*}\right)}{\left[1-\eta\left(b_{t}^{\mathfrak{r}}-\bar{b}^{\mathfrak{r}}\right)\right]},
$$

where the real interest rate on external private debt $r_{t}^{*}=r_{d c, t}+u$ is a premium $u$ over the sovereign's real interest rate on external commercial debt $r_{d c}$ and $\eta$ governs the level of integration the private sector has in international capital markets. ${ }^{7}$

Liquidity-constrained households have the same preferences as Ricardian households but are prevented from saving and borrowing in the domestic and external financial market. These households have therefore to consume as much as their income from wages, remittances, transfers allow, and pay

\footnotetext{
${ }^{6}$ The fraction of liquidity-constrained households in the economy is given by $a>0$.

${ }^{7} \mathrm{~A}$ low $\eta$ depicts the case in which the country has an open capital account with the private sector easily borrowing from abroad.
} 
the same consumption taxes as the Ricardian households, i.e.

$$
\left(1+\tau_{t}^{c}\right) P_{t} c_{t}^{\mathfrak{c}}=w_{t} l_{t}^{\mathfrak{c}}+\frac{a}{1+a}\left(\mathcal{R}_{t}+\mathcal{T}_{t}\right)
$$

\section{Aggregation and Market-Clearing Conditions}

Aggregating across both types of households and firms, we have $x_{t}=\sum_{\substack{i=\mathfrak{r}, \mathfrak{c} \\ j=n, x}} x_{t}^{i, j}$ for $x_{t}^{i, j}=$
$j=$ $c_{j, t}^{i}, l_{j, t}^{i}, i_{t}^{i}, k_{j, t}^{i}, A C_{j, t}^{i}, b_{t}^{i}, b_{t}^{i, *}, y_{j, t}, \Phi_{j, t}^{i}$. Labor markets clear with labor demanded in the tradable and nontradable sectors supplied by both types of households, i.e. $l_{x, t}+l_{n, t}=l_{t}^{\mathfrak{r}}+l_{t}^{\mathfrak{c}}=l_{t}$. Nontradable output produced domestically must match the demand for nontradable goods, public and private investment used in the process of building nontradable public and private capital domestically (with $a_{k}$ and $a_{z}$ defining their nontradable content)

$$
y_{n, t}=\rho_{n}\left(\frac{P_{n, t}}{P_{t}}\right)^{-\epsilon} c_{t}+a_{k}\left(i_{n, t}+i_{x, t}+A C_{n, t}+A C_{x, t}\right)+a_{z i} i_{z i, t}+a_{z a} i_{z a, t} .
$$

Finally, the balance of payment condition must hold

$$
\begin{aligned}
\Delta b_{t}^{*}+\Delta d_{c, t}+\Delta d_{t}+\mathcal{G}_{t}+\mathcal{R}_{t}-\Delta \mathfrak{s}_{t}=- & {\left[P_{n, t} y_{n, t}+P_{x, t} y_{x, t}-r_{t-1}^{*} b_{t-1}^{*}-\Theta_{t}^{\mathfrak{*} *}-\right.} \\
& -r_{d c, t-1} d_{c, t-1}-r_{d} d_{t-1}+r^{f} \mathfrak{s}_{t-1}-P_{t} c_{t}- \\
& \left.P_{z i, t} i_{z i, t}-P_{z a, t} i_{z a, t}-P_{k, t}\left(i_{n, t}-i_{x, t}-A C_{n, t}-A C_{x, t}\right)\right]
\end{aligned}
$$

where the right-hand-side of (21) represents the current account deficit and the left-hand-side the capital account, i.e. the current account balance $c a_{t}=-\Delta b_{t}^{*}-\Delta d_{c, t}-\Delta d_{t}-\mathcal{G}_{t}-\mathcal{R}_{t}+\Delta \mathfrak{s}_{t}{ }^{8}$

\section{Calibration}

The model is tailored to Vanuatu's economy at the time of the natural disaster (2015), calibrating parameters and initial values of endogenous variables using the available literature and data provided by the authorities, the IMF, and other bilateral and multilateral partners when we visited the country in late 2016 in the context of the Article IV consultations (IMF (2016b); Table 1 for initial values and Table 2 for parameters).

\footnotetext{
${ }^{8}$ Under a flexible exchange rate regime $\Delta$ reserves $=0$.
} 


\section{Natural Disaster}

We analyze the response to a known disaster - 2015 Cyclone Pam — for which damages and losses have already been accounted for. We therefore calibrate $D_{j}$ to match Vanuatu's known damages to infrastructure and economic losses following the cyclone. The authorities' Post-Disaster Needs Assessment (2015) details damages and losses amounting to $60.8 \%$ of GDP $(36.7 \%$ in damages and $24.2 \%$ in losses). Damages to the tradable sector, in particular damages and losses in agriculture, industry, and tourism, represented $23.7 \%$ of GDP (45\% of which in damages and the remainder in losses); and $24.7 \%$ to the nontradable sector, which aggregates damages and losses in education and health, communication, energy, environment, transport, and water $(57 \%$ of which in damages and the remainder in losses). The remaining $12.4 \%$ in damages and losses were in private housing.

The distribution of damages and losses among public and private capital destruction and productivity losses reflects our field assessment in Vanuatu. The distribution depends on output elasticities with respect to public infrastructure $\left(\psi_{n}\right.$ and $\left.\psi_{x}\right)$, private capital shares in value added ( $\alpha_{n}$ and $\left.\alpha_{x}\right)$ as well as the severity of damages to public and private capital ( $\varpi_{z}$ and $\varpi_{k}$, respectively). The former are pinned down by the initial return on public infrastructure with $\psi_{n}=\psi_{x}$. Estimates of the rates of return on public infrastructure abound and have been estimated to be between $15 \%$ and $30 \%$ for low-income countries (e.g., Foster and Briceño-Garmendia (2010)), but could also be greater than $50 \%$ depending on the type of infrastructure (Canning and Bennathan (1999)). ${ }^{9}$ For the baseline scenario (separable public capital inputs), the initial return on total public infrastructure $R_{o}^{z}=30 \%$, which by definition equals the gross return on standard public investment $R_{o}^{z i}=30 \%$ given our assumption on $\xi$ as discussed below. On the other hand, estimates on the gross return on public adaptation investment $R_{o}^{z a}$ are much less abundant. Our initial value is high $(50 \%)$ but commensurate with the scarcity of adaptation infrastructure in developing economies or the additional benefit resilient infrastructure provides to the standard infrastructure. ${ }^{10}$ Therefore the implied value of the output elasticities with respect to public infrastructure is 0.0312 . These low elasticities reflect the high inefficiencies in the public investment process. We calibrate the initial efficiency of public investment to be $s_{o}=60 \%$, which is in line with the relative distance of small developing states from one of the most efficient countries in the IMF's PIMA and PIE-X assessments as done in Ghazanchyan et al. (2017).

Public standard infrastructure investment $\left(i_{z i, o}\right)$ is set to 2015 levels and taken from the IMF World Economic Outlook. Adaptation infrastructure was practically nonexistent in Vanuatu at the time Cyclone Pam struck the country and we therefore have $i_{z a, o}=0$ as well as $z_{o}^{a}=0$. Standard and adaptation capital depreciate at the different rates, with the former set at $\delta_{z i}=7.5 \%$ and the latter at $\delta_{z i}=3 \%$, which implies an additional lifespan for adaptation infrastructure of about 75 years relative to standard infrastructure. Private capital shares in value added are computed from the social accounting matrices and input-output tables. The literature suggests a capital share of 55-60\% in the nontradable sector and 35-40\% in the tradable sector for Sub-Saharan African countries. Given the structure of Vanuatu's economy and the limited data availability, we consider the nontradable sector to be more labor-intensive and set $\alpha_{n}=30 \%$, and for the tradable sector we set it in line with other

\footnotetext{
${ }^{9}$ The World Bank requires operations for approval to have internal rates of return of at least $12 \%$.

${ }^{10}$ The seawall or the climate-proofing of a road could extend the average number of days in a year when it is passable, allowing it to operate in less than ideal weather conditions.
} 
low income countries $\alpha_{x}=40 \%$. We calibrate $\varpi_{z}=0.4$ and $\varpi_{k}=0.3$, which gives slightly more weight to the destruction of public capital.

Thus the cyclone causes damages of about $25.8 \%$ of public infrastructure and $25.5 \%$ of private capital relative to steady state. The productivity losses are commensurate, with deviations from the steady state of $20.9 \%$ in the nontradable sector and $20.5 \%$ in the tradable sector. In accordance with accounts of most stakeholders involved in Vanuatu's recovery, a non-negligible fraction of the financial resources deployed were lost in non-productive activities. Thus the magnitude of the public investment efficiency loss $\left(D_{s}\right)$ is assumed to be $20 \%$, which suggests that following the cyclone for every dollar invested an additional 12 cents were lost as a result of the increased uncertainty and bureaucracies. The natural disaster's impact on Vanuatu's credit rating has been contained given its limited exposure to international capital markets (its debt portfolio is mostly concentrated on concessional and semi-concessional borrowing - and thus $\left.\eta_{g}=0\right)$. Nonetheless, S\&P (2015) argues that the largest natural disasters for both earthquakes and tropical storms could lead to downgrades of around 1.5 notches for the sovereigns affected, which includes some low-income countries. A 1-notch downgrade may translate into different levels of deterioration of interest rate spreads and the extent of the downgrade may depend, to name a few, on whether the downgrade means the government's bonds have a speculative grade or not. For that reason, we assume that the country's real interest rate on external commercial debt is aggravated by $15 \%$ (i.e. $D_{r}=0.15$ ) following the natural disaster.

\section{Reconstruction and Recovery}

Vanuatu's major challenge after Cyclone Pam destroyed part of the country's infrastructure was to recover smoothly and start the reconstruction phase as soon as possibly feasible. Economic activity (mostly tourism and agriculture) depends largely on infrastructure provided by the government (roads, ports, and airports) and therefore the political will to have infrastructure running was high. To capture the impetus for a swift recovery, we assume that the government intends to rebuild its damaged infrastructure to its pre-Pam level in about five years. ${ }^{11}$ Public investment efficiency, sectoral TFPs, and the credit risk premium linked to the disaster are all expected to gradually recover to their prePam levels with the economic activity reestablished. The recovery follows a sigmoid function, which depicts the transition from the value of a variable $x$ at the time of the disaster $x^{\text {Pam }}$ to its pre-Pam (steady-state) level $x^{\text {pre-Pam }}$, such that

$$
x_{t}=\exp \left(-\gamma_{x} t\right) x^{\mathrm{Pam}}+\left(1-\exp \left(-\gamma_{x} t\right)\right) x^{\mathrm{pre}-\mathrm{Pam}},
$$

where $x=\left\{z^{i}, s, A_{j}, D_{r}\right\}, \gamma_{x}$ controls the speed of the transition from one state to the other, and $t$ is a vector of time. ${ }^{12}$ Given the path for standard public capital $z_{t}^{i}$, we can retrieve the public investment path for the accelerated reconstruction phase, i.e. $i_{z i, t}^{\text {reconstruction }}=\frac{z_{t}^{i}-\left(1-\delta_{z i}\right) z_{t-1}^{i}}{s_{t}}$. Note that in the absence of the accelerated reconstruction program, the government would still be investing

\footnotetext{
${ }^{11}$ For simplicity, we are considering the case of rebuilding public standard infrastructure. An alternative could be to consider the reconstruction of total public infrastructure and allocate part of the reconstruction to adaptation investments that would capture the argument of "building back better."

${ }^{12}$ Note that $D_{r}^{\text {pre-Pam }}=0$.
} 
$\left(i_{z i, o}\right)$ every period to replenish part of the depreciated capital.

Figure 2 shows the time path for public capital (with and without the accelerated reconstruction) as well as the impact of Cyclone Pam on private capital and TFP for both the traded and nontraded goods sectors. With the accelerated reconstruction program, public capital recovers to its pre-Pam level in less than five years, with public investment peaking at 5.5\% of GDP before gradually declining to its pre-Pam level (1.3\% of GDP) in about 10 years. Without the accelerated reconstruction program, public capital would stay well below its pre-Pam level for a long period of time (as is the case for private capital). Sectoral TFPs take about 6 years to regain their pre-Pam levels, while public investment efficiency recovers in less than 4 years. The 25 basis point increase in the government's real interest rate on external borrowing fades away after about 5 years.

Figure 2: The natural disaster's transmission channel
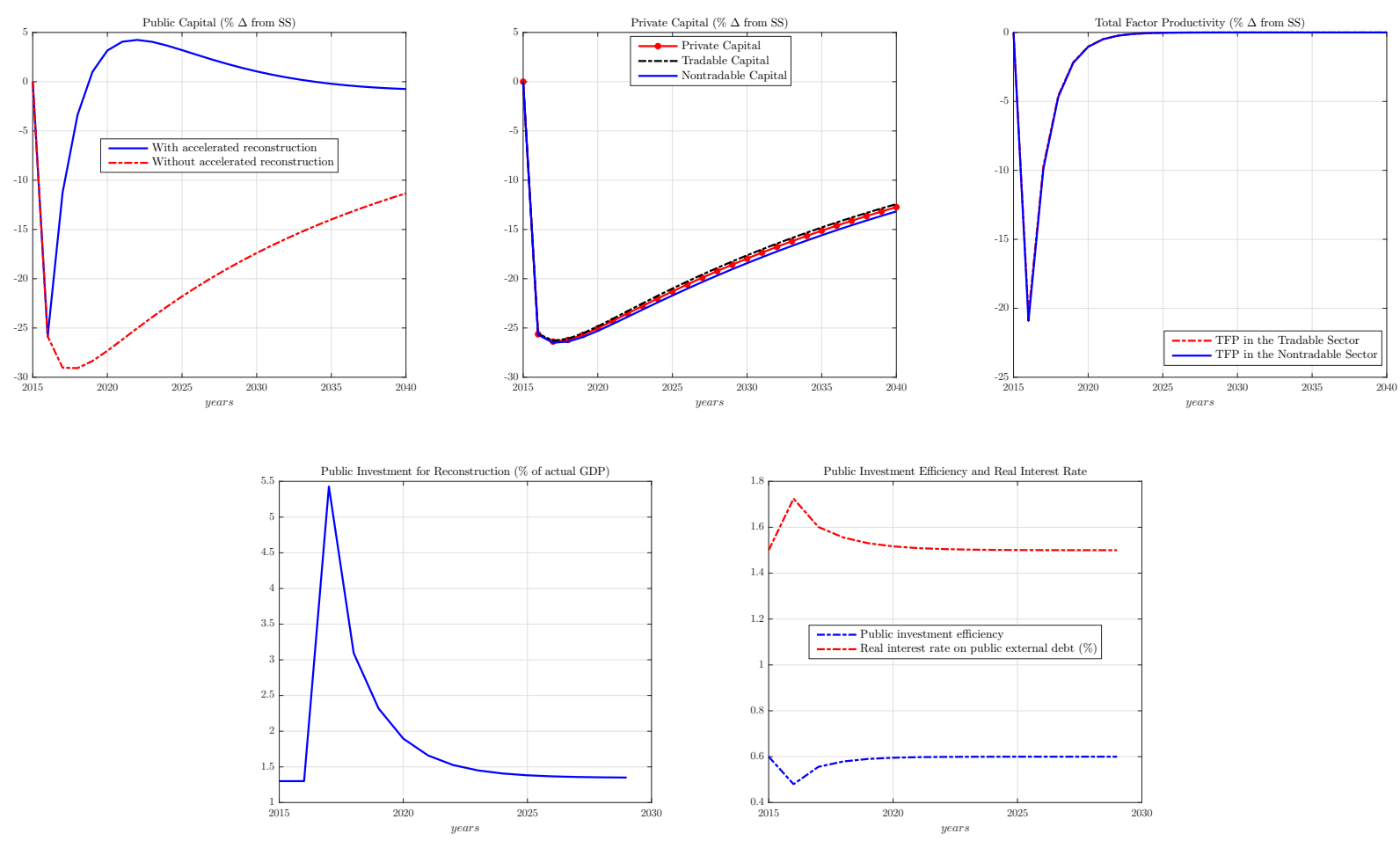

\section{Remaining Calibration}

Public debt levels $\left(b_{o}, d_{o}\right.$, and $\left.d_{c, o}\right)$ were taken from the IMF's 2016 debt sustainability analysis. Vanuatu has little access to international capital markets, so the public external commercial debt corresponds to public semi-concessional debt negotiated with bilateral donors (such as borrowing with the Chinese EXIM bank). Private external debt $\left(b_{o}^{*}\right)$ is taken from the World Bank's (WB) long term private nonguaranteed external debt series. Grants and remittances ( $\mathcal{G}_{o}$ and $\mathcal{R}_{o}$, respectively) are taken from the IMF and based on estimates from the Reserve Bank of Vanuatu and the Ministry of 
Finance. Note that the initial value for grants includes the significant inflows that followed Cyclone Pam during the year of 2015. Since we are interested in donor contributions for the reconstruction phase, we use the 2015 value. Interest rates on debt instruments are set to match recent history. Nominal interest rates tend to be relatively low and thus real interest rates reflect these and relatively low inflation rates in Vanuatu and the world economy. The real interest rate on concessional debt $r_{d}$ is assumed to be zero, as shows recent lending from the Asian Development Bank and the World Bank. The real interest rate on public external debt $\left(r_{d c, o}\right)$ matches the real interest on semi-concessional lending provided by bilateral donors and the real interest rate on public domestic debt $\left(r_{o}\right)$ the effective rate from domestic borrowing excluding state-owned enterprises. The initial tax rate on consumption $\left(\tau_{o}^{c}\right)$ is set at its current statutory level.

Table 1: Selected initial values (\%)

\begin{tabular}{lcc}
\multicolumn{1}{c}{ Definition } & Param. & Value \\
\hline Public standard investment to GDP & $i_{z i, o}$ & 1.3 \\
Public adaptation investment to GDP & $i_{z a, o}$ & 0.0 \\
Return on public standard infrastructure investment & $R_{o}^{z i}$ & 30.0 \\
Return on public adaptation infrastructure investment & $R_{o}^{z a}$ & 50.0 \\
Public domestic debt to GDP & $b_{o}$ & 7.7 \\
Public concessional debt to GDP & $d_{o}$ & 12.9 \\
Public external (commercial) debt to GDP & $d_{c, o}$ & 5.0 \\
Real interest rate on public domestic debt & $r_{o}$ & 5.0 \\
Real interest rate on public concessional debt & $r_{d, o}$ & 0.0 \\
Real interest rate on public external debt & $r_{d c, o}$ & 1.5 \\
Savings to GDP & $\mathfrak{s}_{o}$ & 0.0 \\
Grants to GDP & $\mathcal{G}_{o}$ & 11.2 \\
Consumption tax (VAT) rate & $\tau_{o}^{c}$ & 12.5 \\
Private external debt to GDP & $b_{o}^{*}$ & 0.0 \\
Remittances to GDP & $\mathcal{R}_{o}$ & 3.5 \\
\hline
\end{tabular}

The intratemporal elasticity of substitution between public capital inputs $\xi$ is such that $\frac{\xi-1}{\xi}=1$ (or $\xi=+\infty$ ) in the baseline case, which makes standard and adaptation infrastructure as perfect substitutes and therefore $z_{t}=z_{t}^{i}+\nu_{a} z_{t}^{a}$. In that case, the marginal rate of technical substitution between the public capital inputs is constant and given by $\frac{R_{t}^{z a}}{R_{t}^{z i}}=\nu_{a}$. Although not critical for our experiments, that decision is not without consequences in further model applications. With adaptation and standard public capital being perfect substitutes, a social planner choosing the composition of public investment optimally would prefer to invest entirely in resilient infrastructure since adaptation capital is scarcer, has a lower depreciation rate, and also reduces the impact of natural disasters.

Considering adaptation infrastructure a substitute for standard infrastructure rests on the notion that building seawalls is not the same as building roads or schools. However, adaptation to natural disasters and climate change need not be building seawalls to protect the coastline. There may instead be some complementarity between the two stocks of public capital. One could think of adaptation investments as enhancing bridges to withstand stronger extreme events or climate proofing roads (e.g., 
by using better materials). Departures from our original assumption regarding the complementarity between standard and adaptation infrastructure could take the following forms: (i) the two inputs are perfect complements and thus total public capital is given by the Leontief technology $\min \left(\frac{z_{t}^{i}}{\rho_{z}}, \frac{\nu_{a} z_{t}^{a}}{1-\rho_{z}}\right)$ with $\xi \rightarrow 0$ such that the $\lim \left(\frac{\xi-1}{\xi}\right) \rightarrow-\infty$; and (ii) the two inputs follow a Cobb-Douglas production technology given by $z_{t}=\left(z_{t}^{i}\right)^{\rho_{z}}\left(\nu_{a} z_{t}^{a}\right)^{1-\rho_{z}}$ with $\xi \rightarrow 1$ such that the $\lim \left(\frac{\xi-1}{\xi}\right) \rightarrow 0$. The former would render any increase in one type of investment irrelevant if not done in fixed proportions. The marginal rate of technical substitution between the public capital inputs is such that $\frac{R_{t}^{z a}}{R_{t}^{z i}}=\frac{z i_{t-1}}{z a_{t-1}}$ with $\nu_{a}=\frac{R_{t}^{z a}}{R_{t}^{z i}} \frac{1-\rho_{z}}{\rho_{z}}$. In the latter case, the ratio of marginal benefits would also be a function of the share parameters, i.e., $\frac{R_{t}^{z a}}{R_{t}^{z i}}=\frac{\rho_{z}}{1-\rho_{z}} \frac{z i_{t-1}}{z a_{t-1}}$.

Table 2: Calibrated parameters

\begin{tabular}{lcc}
\multicolumn{1}{c}{ Definition } & Param. & Value \\
\hline Firms & & \\
Capital share in value added in the nontraded goods sector (\%) & $\alpha_{n}$ & 40.0 \\
Capital share in value added in the traded goods sector (\%) & $\alpha_{x}$ & 30.0 \\
Cost share of nontraded inputs in the production of private and public capital (\%) & $a_{k}, a_{z i}, a_{z a}$ & 50.0 \\
\multicolumn{1}{c}{ Households } & & \\
Intertemporal elasticity of substitution of consumption & $\varsigma_{c}$ & 0.34 \\
Intratemporal elasticity of substitution across consumption goods & $\epsilon$ & 0.50 \\
Share of liquidity-constrained households (\%) & $\frac{a}{(1+a)}$ & 12.7 \\
Portfolio adjustment costs parameter & $\eta$ & 1.0 \\
Depreciation rate of private capital (\%) & $\delta_{k}$ & 5.0 \\
& & \\
Intratemporal elasticity of substitution across public capital inputs & $\xi$ & $+\infty$ \\
Depreciation rate of standard infrastructure (\%) & $\delta_{z i}$ & 3.0 \\
Depreciation rate of adaptation infrastructure (\%) & $\delta_{z a}$ & 7.5 \\
User fees fraction of recurrent spending (\%) & $\mu$ & 50.0 \\
Premium on imported machinery for adaptation infrastructure (\%) & $p r$ & 0.0 \\
Public debt risk premium parameter & $\eta_{g}$ & 0.0 \\
Risk-free world real interest rate (\%) & $r^{*}$ & 2.0 \\
\hline
\end{tabular}

From the remaining parameters, we highlight the following. The share of liquidity-constrained households is calibrated from the latest WB reported poverty headcount ratio at the national poverty lines (as \% of population). This figure appears to be low and may not reflect the exact fraction of the population without access to credit. On the other hand, increasing the share of liquidity-constrained households would exacerbate the impact of fiscal policies on private consumption and investment. The fee Ricardian households pay on standard public infrastructure $(\mu)$ is a fraction of the recurrent costs. Given the considerable variation in recurrent costs, we assume that the government charges $50 \%$ of its costs to households. Imports to GDP, used to pin down the share parameters in the CES consumption basket, are taken from the IMF as imports of goods (54\%), while the share parameter in the CES public capital definition is tilted in favor of standard public infrastructure (90\%) . The value added in nontradable sectors, used to compute the share of output in the nontraded sector, are estimates from 
the sectoral aggregation of nontradable activities in value added from national accounts (48\%).

\section{Recovering with Fiscal and Debt Sustainability}

In this section we study how the government would have had to respond to the natural disaster if it had to finance the entire reconstruction activities by either raising consumption taxes or resorting to external borrowing. Then we assess what aid package should donors have provided the government to ensure fiscal and debt sustainability over the medium term, i.e. allowing the government to maintain similar debt levels without raising taxes.

\subsection{Alone in the Dark}

This subsection examines the fiscal and debt implications of financing the government's accelerated reconstruction without further support from its development partners. Figure 3 presents the time path of selected endogenous variables, illustrating the macroeconomic implications of the two scenariosone in which the fiscal gap is entirely financed with consumption taxes and the other in which external borrowing adjusts to close the fiscal gap. Although the impact on real GDP of these two financing schemes is similar, increasing taxes is far more damaging to households than the additional debt. The government would have to raise the consumption tax rate from $12.5 \%$ to close to $23 \%$ in the short term and to about $14 \%$ over the medium term. As a result, private consumption would drop $20 \%$ relative to its pre-Pam level. Resorting to external borrowing has a smaller effect, with private consumption falling less than with a tax-financed reconstruction. Although Ricardian households base their optimal decisions on the entire profile of government debt and taxes, an increase in taxes affects both types of households. On one hand, liquidity-constrained households have to consume as much as their disposable income allows, thus an increase in taxes has a direct effect on their disposable income. On the other hand, the increase in taxes and domestic real interest rates affect Ricardian households intertemporal consumption decision, with the latter increasing sharply with the spike in taxes (from $5 \%$ to $18 \%)$.

Increasing taxes would be at odds with the authorities' goal to smooth the impact on households' consumption. In response to the cyclone the government suspended VAT and import duties on construction materials to boost reconstruction of damaged infrastructures and allowed members of the National Provident Fund (mostly civil servants) to withdraw up to $20 \%$ of their retirement savings. However, the alternative scenario of resorting entirely to external borrowing poses threats to the government's debt sustainability. The debt-financed accelerated reconstruction phase would push public debt to levels well above $90 \%$ of GDP in the medium term - which could reach above $105 \%$ of GDP in 30 years - from $25 \%$ pre-Pam. The resulting appreciation of the real exchange rate (4\%) makes the tradable sector lose some price competitiveness and the current account deficit to worsen to about $9 \%$ of GDP. The negative impact on the tradable sector is 5 percentage points stronger relative to its Pre-Pam level when the government resorts to borrowing as opposed to taxes. 
Figure 3: Debt and fiscal sustainability implications
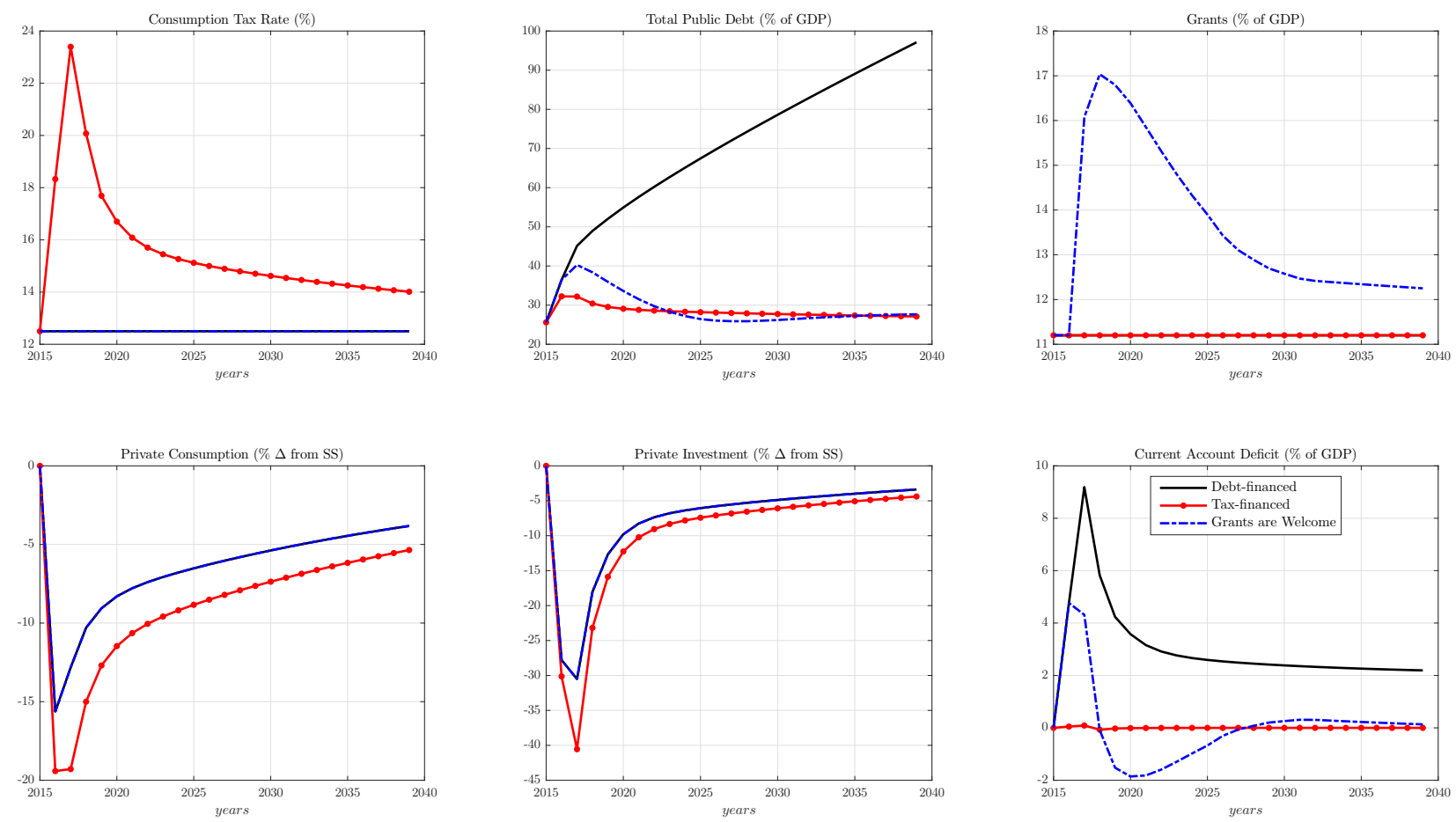

Private investment falls more under the tax-financed reconstruction program, with a very strong decline in investment in both the tradable and nontradable sectors (about 40 and $42 \%$, respectively)despite similar rates of return on tradable and nontradable capital (2 percentage points above their initial values). Private capital, as a result, trails below the path implied by debt-financed reconstruction. In both cases, the capital stocks are $20 \%$ below the pre-Pam level for more than 10 years. All in all, both financing strategies entail significant risks and a challenging recovery over the medium term. Despite the benefits of accelerating the reconstruction process, restoring the level of public infrastructure that prevailed prior to the disaster may require adjustments that are politically infeasible.

\subsection{Grants for Reconstruction}

In this subsection we address the fiscal and debt sustainability concerns discussed previously by considering that the donor community is willing to help the government realize its accelerated reconstruction program, such that it would not need to raise taxes or resort to additional borrowing. Depicted in blue, Figure 3 also shows the time path of the endogenous variables for the case with external grants closing the government's budget constraint. Grants are provided exogenously, mimicking the large inflow of grants needed to sustain the accelerated reconstruction program. In order to finance the accelerated reconstruction program, donors would have to contribute significant resources over the medium term: an additional 50\% of pre-Pam GDP in grants for over 15 years after the cyclone. The bulk of grants would be provided in the first five years, peaking at 17\% of (actual) GDP and staying 
above $12 \%$ of GDP over the medium term before returning to its 2015 level in the long run-which per se was a remarkable increase in grants relative to the years prior to Pam. This financing package far outweighs the large commitments several development partners have made to Vanuatu over the next few years. And with the benefit of hindsight, we indeed confirm that grants (in terms of GDP) have not followed suit, in spite of the initial commitments - yet short in disbursements - of bilateral and multilateral donors following the cyclone. This suggests that the pace of reconstruction activities will have to be slower than expected and that important infrastructure projects may take more time to materialize.

On the other hand, the benefits of a grant-financed reconstruction program are clear: the country enjoys the benefits (or lesser evil) of a debt-financed recovery without the debt distress concerns. Thanks to the lower debt levels, the current account is stabilized in about 15 years after the cyclone. Another important consideration to have in mind with regards to the grant contribution of bi and multilateral donors is that these encompass far more than financial support. External grants often come with substantial technical assistance, enforcing stricter rules regarding procurement — ensuring public investment is well spent and thus investment efficiency is sustained - as well as enhancing the functioning of institutions to help cope with the disaster's consequences - allowing households to recover their work and hence boosting a productivity recovery. Adding these features to our simulations would show a stronger recovery of private consumption and investment, with real GDP converging to its initial steady state at a faster rate. Note also that "aid fatigue" concerns may arise with prolonged donor support, which may dampen the government's incentives to efficiently collect tax revenues.

\section{Building Resilience with Adaptation Infrastructure and Fiscal Buffers}

The previous section analyzed how the government could rebuild the damaged infrastructure after the disaster ravaged the country. In contrast, this section focuses on what policies could the government have implemented prior to the natural disaster with the support of donors. We consider two such policies: (i) investing in adaptation infrastructure; and (ii) saving proceeds in an external contingency fund.

\subsection{Investing in Resilient Infrastructure}

This subsection performs the following thought experiment: suppose the government had spent $3 \%$ of GDP per year in adaptation infrastructure in the five years prior to Cyclone Pam - expenditures entirely funded by donors - what would have happened to debt and fiscal sustainability? For comparability purposes, we assume the same accelerated reconstruction path post disaster despite the smaller destruction of public infrastructure. Thanks to the investment in resilient infrastructure, the magnitude of the cyclone's damages to public and private infrastructure, as well as on sectoral TFP is reduced. Thus, the fiscal gap that needs to be financed provides an upper bound for public debt since 
post-disaster the government builds more public capital than it would have built under the previous scenario. Figure 4 shows the magnitude of the damages and contrasts the previous section's paths of public and private capital and TFP in blue with the ones obtained from investing in resilent infrastructure in red. Investing in adaptation would have reduced damages to standard public infrastructure (e.g. roads) by $5.2 \%$, by $9.7 \%$ the damages to private capital, and by $3.8 \%$ and $3.9 \%$ the productivity losses in the tradable and nontradable sectors.

Figure 4: More resilient infrastructure, lower damages
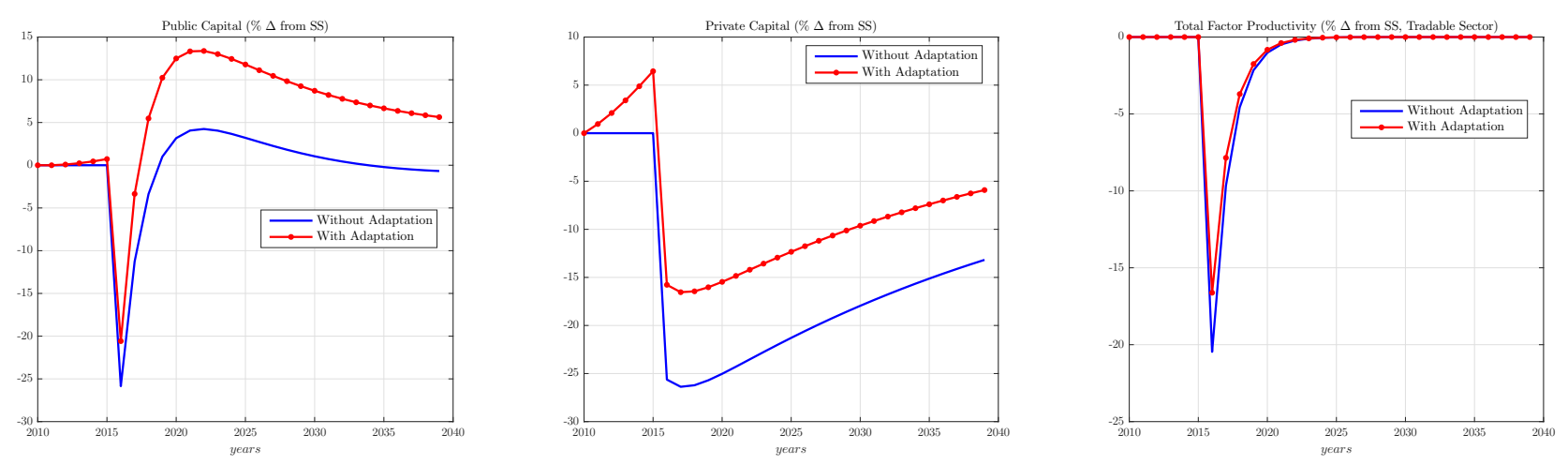

Figure 5 presents the results for both the debt and tax-financed reconstruction programs following public investments in resilient infrastructure. Fiscal and debt sustainability concerns are attenuated thanks to the build up of resilient capital. Investing in adaptation helped reduce the risks of debt distress, with public debt reaching less than $60 \%$ of GDP over the medium term (as opposed to $100 \%$ of GDP in the previous subsection), while the tax-financed reconstruction program requires a less demanding fiscal adjustment. In that case, the consumption tax rate would have to increase to $21 \%$, yet reverting much faster to its initial value (in about five years as opposed to a prolonged tax increase in the scenario with no adaptation investment). Note that investing in adaptation raises the marginal product of private capital, crowding in private investment prior to the disaster together with the increase in the domestic real interest rate. In contrast, this gives rise to a contraction of private consumption in the short term - in particular from the savers. Post-disaster, private investment declines by about $23 \%$ to $31 \%$ relative to the initial steady state - a 10 percentage point difference with the previous scenario - while private consumption decreases by about 10 to $12 \%$.

\subsection{Building Fiscal Buffers}

A common advice to countries facing a high probability of a large shock is to accumulate money in a contingency fund. The reason for that is that access to financing (particularly external financing) might be curtailed or become prohibitively expensive exactly when the government needs money to deal with a shock. This is, for example, a rationale for holding international reserves despite their high opportunity cost. With that in mind, this subsection answers the following: what if the government had decided to reallocate part of its intended capital spending on resilient infrastructure in a contingency fund instead? The government and donors decide to allocate annually half of the $3 \%$ of GDP in a 
Figure 5: Resilient infrastructure reduces risk of debt distress
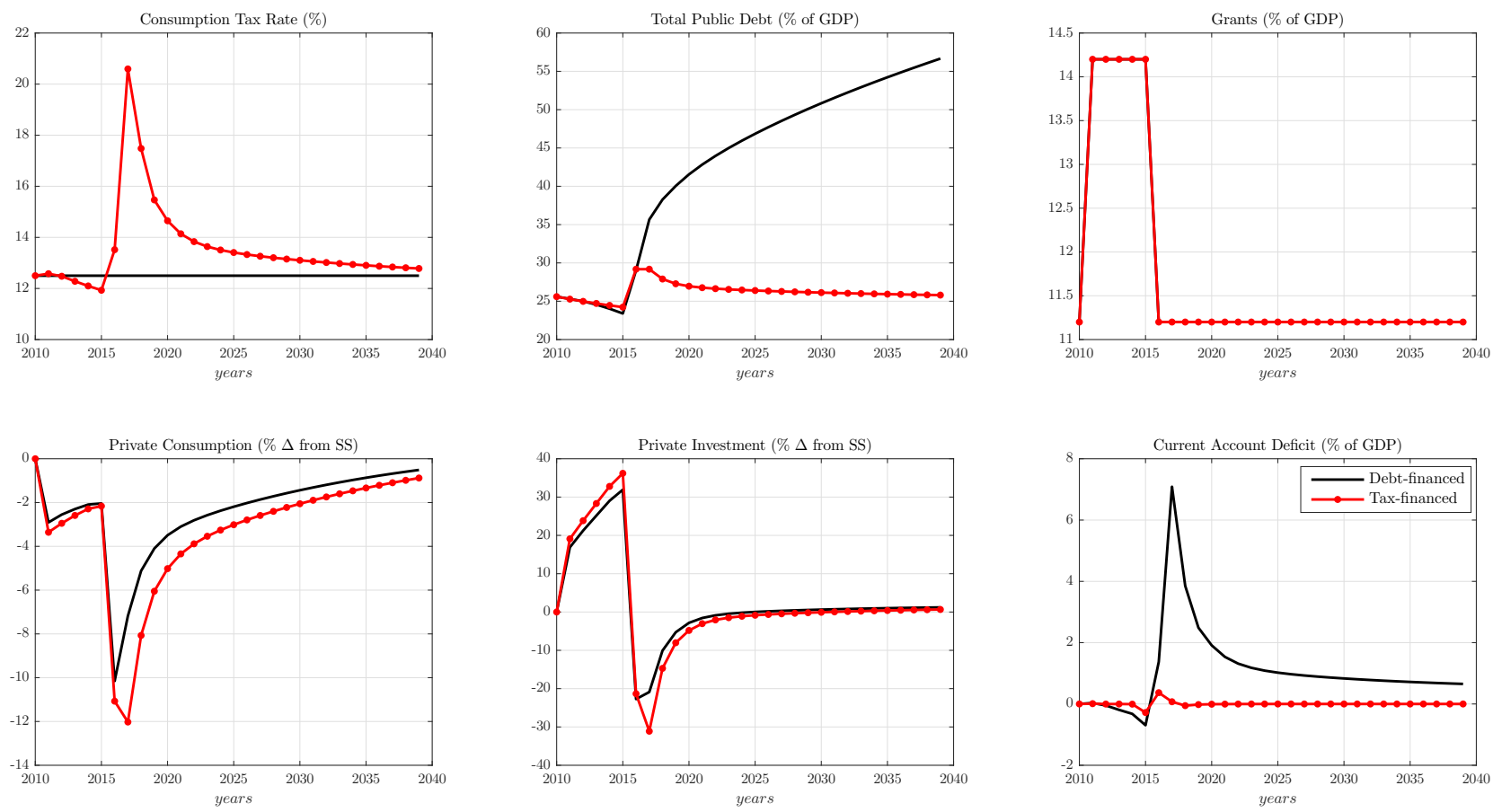

contingency fund and the other half in adaptation investments. Figure 6 contrasts this scenario (in red) with the case in which the government invests the $3 \%$ of GDP only in adaptation (from the previous subsection; in blue) and the case in which the government has no donor support and does not adopt any preemptive measures (from subsection 4.1; in black); in all these scenarios, external borrowing closes the government's fiscal gap.

With the support of donors, the government accumulates about $8 \%$ of GDP in its external contingency fund that is then used to fund reconstruction (withdrawals amount to $75 \%$ of the fund's remaining balance for three years after the disaster). The availability of financial resources allows the government to start reconstruction without the need for additional borrowing in the short term. Building fiscal buffers allows the government to live with lower debt-to-GDP levels compared with only investing in resilient infrastructure over the medium term-note also that GDP is more affected in the former than in the latter - however, the gains subside by 2035 with total public debt reaching $53 \%$ of GDP. On the other hand, both preemptive policies lead to lower debt levels than warranted under the post-disaster reactive policy (about 25 percentage points lower).

Diverting part of the investment in adaptation to the contingency fund has both a direct and an indirect effect on GDP. First, it reduces the stock of resilient infrastructure that helps withstand the impact of the storm and thus there is more destruction of public and private capital. On the other hand, the scarcity of adaptation capital raises its marginal benefit, which sustains the crowding in of private investment prior to the disaster. Relative to its initial value, investing entirely in adaptation saved the economy 3 percentage points of its output relative to the strategy of coupling adaptation 
investments with savings - and note that adaptation investments are not fully efficient. Although the tax rate is fixed, private consumption still drops $12 \%$ below its initial value upon the shock with the domestic real interest rate reaching negative values. With the expectation of the storm coming, households are trading today's consumption for more consumption in the future. Then, given the low real interest rate, private consumption rebounds immediately but stays below pre-Pam level for several decades. On the other hand, adjusting taxes to finance the reconstruction would have further dampened the contraction of private consumption.

Figure 6: Saving in a contingency fund helps smooth the recovery
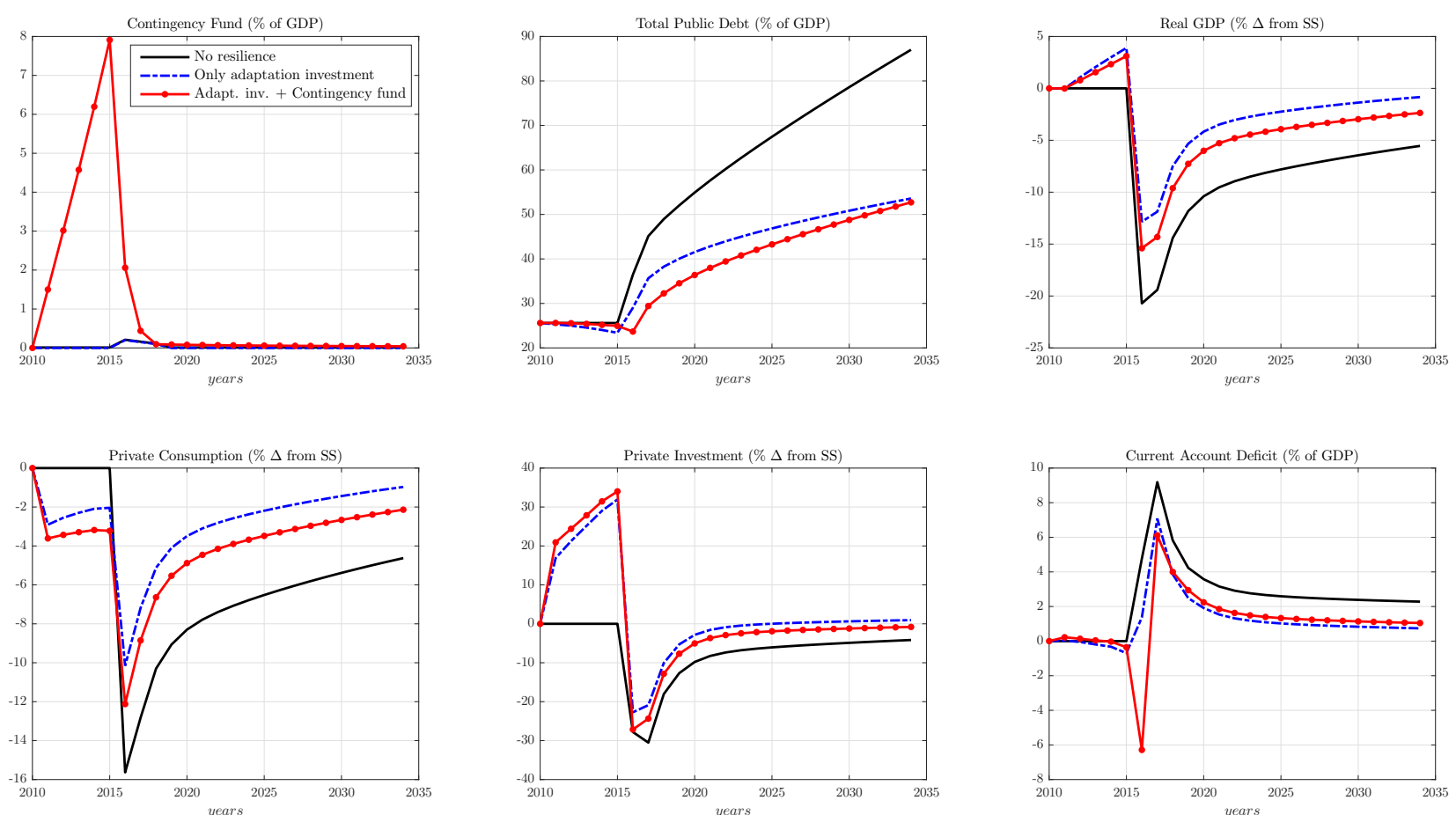

So all in all, should a small developing country susceptible to natural disasters invest in a contingency fund? The answer depends on what sort of event it needs to insure itself against - including the size of the shock and the reaction of the international community. Relatively frequent (occurring once every few years) events of manageable proportions (e.g., with damages in the order of $1 \%$ of GDP) are unlikely to elicit a major response from development partners. If the country has to deal with the consequences of such events largely on its own, a permanent income hypothesis argument suggests that accumulating resources in a contingency fund during non-disaster years would allow avoiding costly adjustments in disaster years - which should be welfare-improving. ${ }^{13}$ Contributions to the fund could correspond to the average cost of "non-catastrophic" disasters (e.g., if there is one in five chance every year of a shock that costs $1 \%$ of GDP, then $1 / 4 \%$ of GDP should be deposited in the contingency fund

\footnotetext{
${ }^{13}$ Another way to think about this is that both the cost of borrowing and the opportunity cost of not investing in infrastructure are likely to be higher after a natural disaster than in quiet times, so it makes sense to "pre-fund" the recovery and reconstruction expenditures that the government knows it is going to incur with near certainty over a few years.
} 
every non-disaster year).

That same argument does not apply to truly catastrophic events like cyclone Pam. As discussed above, trying to finance reconstruction on its own would undermine the country's development. It has to rely on external support and the international community is very likely to come to the rescue. By the same token, the country cannot divert enough resources into a contingency fund to deal with a possible future cataclysmic event without stunting its development. Accumulating some money to cover a fraction of the cost would alleviate the burden on the donors, but unless there is a credible mechanism to commit the country to cost-sharing in case of a major natural disaster, it would not be rational for a developing country to try and save money to its development partners. For the same reasons, small states might see purchasing catastrophe insurance as a wasteful transfer to more developed economies, as the latter would likely decrease the amount of their post-disaster aid by the size of the insurance payout.

One could make an argument that it would be useful for the small state to have some money in the contingency fund because even if ultimately the bulk of reconstruction expenses is financed by donors, it takes a while for them to put the package together, and in the meantime the government should have some cash on hand to finance immediate needs. That is true to an extent and such needs could be served by a small contingency fund advocated in the previous paragraph and other liquid resources the government has (foreign reserves; government deposits). It should be noted, however, that with the disruption that the cyclone caused on Vanuatu and the country's remoteness, cash alone would have solved very few problems. The shortages of food, potable water, shelter, electricity, and other essential goods and services could not have been resolved simply by purchasing those. Their delivery and help with repairing essential infrastructure had to be largely organized by the donors anyway. Finally, for the donors themselves, pre-funding a response to a possible future natural disaster in a foreign country would not be beneficial as they would not face liquidity constraints post-disaster in any case (unlike the affected country).

On the other hand, as demonstrated above, investing in building resilience to natural disasters could pay off should one occur. Even for the donors, in the long run it would likely be cheaper to finance resilient infrastructure in small developing states than to help them deal with the consequences of unmitigated shocks - although politically it might be easier to mobilize support for a country hit by a highly visible shock than to finance its infrastructure program.

\section{Conclusions}

Small developing states are frequently hit by natural disasters that tend to leave long-lasting scars in the economy. In addition to deaths of a non-negligible fraction of the population, natural disasters destroy public and private infrastructure needed for the economy to function, disrupting economic and social activities with long-lasting effects. They also put considerable strains on government finances, frequently demanding a swift reconstruction of major infrastructures - yet with limited room to raise additional revenues or curtail transfers and other expenditures. Although these issues are macro- 
critical, they have been little explored in the literature.

This paper assesses two main policy issues: (i) if the government were to fully rebuild the public infrastructure destroyed by the cyclone in less than a decade, what additional resources would the donor community have to pitch in to ensure fiscal and debt sustainability over the medium term?; and (ii) if the government were to invest in resilient infrastructure and save financial resources in a contingency fund, how fiscal and debt sustainability would be improved after the disaster? In an application to Vanuatu, severely hit by Cyclone Pam in March 2015, we show the following. First, the country cannot face damages alone: grant-fathering is key for debt sustainability. In spite of the moral hazard issues linked with such a strategy, bi and multilateral partners would have to significantly scale up their financial contributions following the cyclone if the donor community wants to ensure a smooth recovery. Second, the government can, and should, invest in resilient infrastructure and build fiscal buffers that would attenuate the impact of the disaster. However, these initiatives imply some policy choices head-on: the government would need to create fiscal space (raising taxes or reducing other expenditures) or resort to borrowing. Finally, and more importantly, donors can help make these investments. This would help reduce the need for their financial contributions post-disaster. We shall however not fool ourselves: recovering from a highly damaging natural disaster will still demand significant financial contributions from donors, even with a reasonable level of adaptation infrastructure - hence grant-fathering is essential.

These results show the important role the donor community may play in sustaining a swift recovery in countries severely hit by natural disasters. Possible extensions of this model could study the optimal balance between ex ante and ex post policies for both policymakers and donors, or alternatively consider different damage functions (which could include temperature or wind speeds) and assess the impact of climate change on growth and debt sustainability. On the other hand, the policy dialogue could revolve around the following issues: incorporating disaster costs into budget planning (e.g. average impact on growth, increased infrastructures' depreciation rates and maintenance costs); building fiscal buffers and investing in infrastructure able to the withstand the impact of a disaster (including urban planning and integrated coastal zone management); and enhancing the framework for coping with natural disasters (national plan, institutions, and responsibilities) to accelerate the recovery process and reduce the impact on productivity and investment efficiency. 


\section{References}

Adam, C. and D. Bevan, 2006, "Aid and the Supply Side: Public Investment, Export Performance, and Dutch Disease in Low-Income Countries," The World Bank Economic Review, Vol. 20(2), pp. 261-290.

Bakkensen, L. and L. Barrage, 2017, "Do Disasters Affect Growth? A Macro Model-Based Perspective on the Empirical Debate," Working Paper.

Barro, R., 1990, "Government Spending in a Simple Model of Endogenous Growth," Journal of Political Economy, Vol. 98(5), pp. 103-125.

Barro, R. and X. Sala-i-Martin, 1992, "Public Finance in Models of Economic Growth," Review of Economic Studies, Vol. 59(4), pp. 645-61.

Becerra, O., Cavallo, E., and I. Noy, 2014, "Foreign Aid in the Aftermath of Large Natural Disasters," Review of Development Economics, Vol. 18(3), pp. 445-460.

Bevan, D. and C. Adam, 2016, "Financing the Reconstruction of Public Capital after a Natural Disaster," World Bank Policy Research Working Paper 7718.

Bevan, D. and S. Cook, 2015, "Public Expenditure Following Disasters," World Bank Policy Research Working Paper 7355.

Borensztein, E., Cavallo, E., and O. Jeanne, 2017, "The Welfare Gains from Macro-Insurance Against Natural Disasters," Journal of Development Economics, Vol. 124, pp. 142-156.

Buffie, E., Berg, A., Pattillo, C., Portillo, R., and L.F. Zanna, 2012, "Public Investment, Growth and Debt Sustainability: Putting Together the Pieces," IMF Working Paper 12/144.

Burke, M., Hsiang, S., and T. Miguel, 2015, "Global Non-linear Effect of Temperature on Economic Production," Nature.

Canning, D. and E. Bennathan, 1999, "The Social Rate of Return on Infrastructure Investments," World Bank Policy Research Working Paper 2390.

Cavallo, E. and I. Noy, 2011, 'Natural 'Disasters and the Economy: S Survey," International Review of Environmental and Resource Economics, Vol. 5(1), pp. 63-102.

Cavallo, E., Galiani, S., Noy, I., and J. Pantano, 2013, "Catastrophic Natural Disasters and Economic Growth," The Review of Economics and Statistics, Vol. 95(5), pp. 1549-1561.

Dabla-Norris, E., Brumby, A. K., Mills Z., and C. Papageorgiou, 2012, "Investing in Public Investment: An Index of Public Investment Efficiency," Journal of Economic Growth, Vol. 17(3), pp. 235-266.

Foster, V. and C. Briceño-Garmendia, 2010, Africa's Infrastructure: A Time for Transformation, Agence Francaise de Developpement and the World Bank.

Futagami, K., Morita, Y., and A. Shibata, 1993, "Dynamic Analysis of an Endogenous Growth Model with Public Capital," Scandinavian Journal of Economics, Vol. 95(4), pp. 607-25.

Ghazanchyan, M., Marto, R., Jonas, J., and K. Douglass, 2017, "Collect More, Spend Better: Public Investment in Asian Frontier Markets," IMF Working Paper 17/10.

Government of Vanuatu, 2015, "Post-Disaster Needs Assessment - Tropical Cyclone Pam."

Ikefuji, M. and R. Horii, 2012, "Natural Disasters in a two-sector model of endogenous growth," Journal of Public Economics, Vol. 96(9), pp. 784-796. 
International Monetary Fund, 2016a, "Small States' Resilience to Natural Disasters and Climate Change - Role for the IMF," IMF Policy Paper.

International Monetary Fund, 2016b, Vanuatu Article IV Staff Report, IMF Country Report 16/336.

Intergovernmental Panel on Climate Change, 2014, "Fifth Assessment Report - Climate Change 2014: Impacts, Adaptation, and Vulnerability."

Noy, I., 2009, "The Macroeconomic Consequences of Disasters," Journal of Development Economics, Vol. 88(2), pp. 221-231.

Schmitt-Grohe, S. and M. Uribe, 2003, "Closing Small Open Economy Models," Journal of International Economics, Vol. 61(1), pp. 163-185.

Standard \& Poor's, 2015, "Storm Alert: Natural Disasters Can Damage Sovereign Creditworthiness." 